\title{
Slope Aspect Affects The Soil Microbial Communities In Karst Tiankeng Negative Landforms
}

\section{Cong Jiang}

Peking University

Wei Shui ( $\nabla$ shuiwei@fzu.edu.cn )

Fuzhou University

\section{Su-Feng Zhu}

Chinese Research Academy of Environmental Sciences

Jie Feng

Fuzhou University

\section{Research Article}

Keywords: Karst tiankeng, Slope, Microbial community, Heterogeneity, Metagenomics

Posted Date: September 7th, 2021

DOI: https://doi.org/10.21203/rs.3.rs-779886/v1

License: (a) (i) This work is licensed under a Creative Commons Attribution 4.0 International License. Read Full License 


\section{Abstract}

Background: Karst tiankeng is a large-scale negative surface terrain, and slope aspect affect the soil conditions, vegetation and microbial flora in the tiankeng. However, the influence of the slope aspect on the soil microbial community in tiankeng has not been elucidated.

Methods: In this study, metagenomic sequencing technology was used to analyzed the soil microbial communities and metabolic function on the shady and sunny slopes of karst tiankeng.

Results: The Shannon-Wiener diversity of microbial communities on shady slopes was significantly higher than that on shady slopes. Shady and sunny slopes have similar microbial community composition, but there are differences in abundance. The linear discriminate analysis (LDA) results showed that biomarkers mainly belongs to Actinobacteria, Chloroflexi and Proteobacteria. Functional pathways and CAZy (Carbohydrate-Active Enzymes) genes also had a remarkable response to slope aspect change. LEfSe results indicated several biomarker pathways in sunny slope involved in human disease. Moreover, the abundance of CAZy genes was higher in shady slope and had stronger ability in decomposing litter. The microbial communities were mainly correlation with the vegetation characteristics (species richness and coverage) and soil properties (SOM and pH).

Conclusions: These results indicate slope aspect has a pronounced influence on microbial community composition, structure and function at karst tiankeng. In the future, the conservation of karst tiankeng biodiversity should pay more attention to topographical factors.

\section{Background}

The karst tiankeng is a special and grand negative surface terrain first discovered in the karst area of southern China at the end of the 20th century [1]. Affected by the steep rock wall and its own depth, a local microclimate different from the surface of the tiankeng has been formed inside the tiankeng, which has nurtured unique resources of animals, plants and microorganisms [2-5]. As we all know, human activities have caused environmental problems such as rocky desertification, loss of land resources, and ecosystem degradation in karst areas, turning them into vulnerable and sensitive areas of the ecological environment [6-7]. The unique ecological environment of tiankeng makes it like an oasis in a degraded karst landscape [5].

China is the kingdom of karst tiankengs, which occupies more than $70 \%$ of the world's total tiankengs, and has preserved a more systematic and complete chain of tiankeng evolution [8]. At present, most research focuses on the formation and evolution mechanism of tiankeng [9], plant diversity [3,10], and tourism resource value [11]. However, there are few studies on the distribution of microbial resources and their mechanism of action in the karst tiankeng ecosystem. Pu et al. [4] and Jiang et al. [12] results showed that the distribution of microbial communities in the karst tiankeng ecosystem has obvious heterogeneity. As the most diverse and species-rich taxa on earth, soil microorganisms promote the energy flow and material transformation of the ecosystem and maintain the normal operation of the 
ecosystem $[13,14]$. Therefore, investigating the structure and function of the soil microbial community is very necessary for exploring the generation of biological diversity in tiankeng and the prediction of the evolution direction of ecosystem functions.

Slope aspect is one of the main topographical factors, which will cause differences in solar radiation, temperature, precipitation and soil texture, which in turn will cause differences in soil nutrients and microbial communities $[15,16]$. Previous studies have shown that the slope aspect has a significant impact on the microbial characteristics $[17,18]$. Some studies have found that north slopes have higher microbial biomass carbon (MBC) and relative abundance of Gram-negative bacterial than south slope [17]. However, other studies have shown that the total phospholipid fatty acid, diversity of bacterial and fungal in the south slope were higher than north slope [19]. These results reflect the obvious influence of slope aspect on microbial community characteristics. The karst tiankeng is affected by the shelter of vertical cliffs, and the habitats of shaded and sunny slopes are distinctly different. Our previous research has found the soil properties and microclimate of shady and sunny slopes in karst degraded tiankeng were dramatically different, which results in obvious differences in the types of plant communities [20]. However, the relationships between in topographic distribution of microbial communities and soil physicochemical properties in karst tiankeng were rarely investigated. Affected by the effect of karst tiankeng traps, the influence of slope aspect on the microclimate may become more important. It is vital to understand how environmental constraints affect the microbial communities in karst tiankeng. Furthermore, understanding the characteristics of the microbial community related to the slope aspect is of great significance for clarifying the role of soil microorganisms in the function of the tiankeng ecosystem. In the present study, the characteristics of microbial community between the shady and sunny slope were analyzed in the karst tiankeng. The relationship between environmental factor and microbial community were established, simultaneously. This research aims to provide reference and scientific basis for the conservation of karst tiankeng biodiversity and the understanding of soil ecological processes.

\section{Results}

\section{The soil physicochemical properties on the different slope}

The plant characteristics differed between the shady slope and sunny slope (Table 1). The plant species richness was significantly higher in SHS $(P<0.05)$. Significant differences in plant coverage were also found between the SHS and SUS $(P<0.05)$. The Shannon-Wiener index was higher in SHS, but no significant differences were observed between SHS and SUS.

The SOM and TN were higher in SHS, but no significant difference between the SHS and SUS was observed (Table 2). In addition, the TP was higher in SUS. TK and SWC were significantly higher in SHS ( $P$ $<0.05)$. The soil pH values in SHS and SUS were 6.64 and 7.12, respectively. There was significant differences in the pH between the SUS and SHS $(P<0.05)$.

Table 1 The characterization of the plant communities feature on the different slopes. 


\begin{tabular}{cllll} 
& $\begin{array}{l}\text { Species } \\
\text { richness }\end{array}$ & $\begin{array}{l}\text { Coverage } \\
(\%)\end{array}$ & $\begin{array}{l}\text { Shannon-Wiener } \\
\text { index }\end{array}$ & Dominant species \\
\hline SHS & $42.8 \pm 3.70 \mathrm{a}$ & $76.2 \pm 4.32 \mathrm{a}$ & $2.06 \pm 0.17 \mathrm{a}$ & $\begin{array}{l}\text { Myrsine africana Linn. } \\
\text { Debregeasia orientalis } \mathrm{C} \text {. J. Chen } \\
\end{array}$ \\
& & & & $\begin{array}{l}\text { Ternstroemia gymnanthera (Wight et Arn.) } \\
\text { Beddome }\end{array}$ \\
SUS & $29.8 \pm 5.06 \mathrm{~b}$ & $60.0 \pm 5.94 \mathrm{~b}$ & $1.77 \pm 0.12 \mathrm{a}$ & $\begin{array}{l}\text { Quercus guyavifolia } \\
\text { Quercus variabilis Bl. }\end{array}$ \\
& & & &
\end{tabular}

Table 2 The characterization of the soil physicochemical properties on the different slopes.

\begin{tabular}{lllllll} 
& SOM & TN & TP & TK & pH & SWC \\
\hline SHS & $66.48 \pm 2.94 \mathrm{a}$ & $2.84 \pm 0.55 \mathrm{a}$ & $0.45 \pm 0.08 \mathrm{a}$ & $12.48 \pm 1.40 \mathrm{a}$ & $6.64 \pm 0.21 \mathrm{~b}$ & $0.44 \pm 0.03 \mathrm{a}$ \\
\hline SUS & $58.95 \pm 3.84 \mathrm{a}$ & $2.43 \pm 0.36 \mathrm{a}$ & $0.49 \pm 0.12 \mathrm{a}$ & $9.22 \pm 2.17 \mathrm{~b}$ & $7.12 \pm 0.17 \mathrm{a}$ & $0.37 \pm 0.03 \mathrm{~b}$
\end{tabular}

\section{Variation on microbial community diversity and composition on the different slopes}

The Shannon-Wiener index was significantly higher in SHS $(P>0.05)$ (supplementary Fig. S1). The ANOSIM analysis results $(\mathrm{R}=0.612, P=0.012)$ showed that soil microbial community from shady slope and sunny slope were significantly different (supplementary Fig. S2). The PCoA results exhibited that microbial community in SHS were separately from those in SUS (Fig. 1).

According to the metagenomic analyses, the highest number of sequences corresponded to bacteria, followed by archaea, fungi and viruses. As shown in Fig. S3, Proteobacteria was the most abundant bacteria phylum in SHS and SUS soil sample, and followed by Actinobacteria, Chloroflexi, Acidobacteria and Verrucomicrobia. In addition, twelve archaea phylum were obtained. The most abundant archaea phylum were Euryarchaeota, Thaumarchaeota and Candidatus_Bathyarchaeota. As an important part of soil microbes, the kingdom fungi consisted of nine phyla. Among them, the phylum Ascomycota and Basidiomycota were the most abundant.

The microbial community compostion at the genus level (abundance $>1 \%$ ) is shown in Fig. 2. The most abundant genus in both soil samples was Bradyrhizobium and the abundance ranged from $4.31 \%-9.04 \%$. In addition, Streptomyces (2.17\%-3.25\%), Acidobacteria_noname (2.32\%-2.47\%), Betaproteobacteria_noname (2.06\%-2.31\%), Bacteria_noname (1.99\%-2.35\%) and Cand_Candidatus_Rokubacteria_noname (1.45\%-2.60\%) were the shared by both soil samples. Furthermore, veen diagrams showed the shared and unique species between the SHS and SUS. The shared species between them was 16,105, and unique species was 836 and 443 in SHS and SUS, respectively (Fig. 3). 
The LEfSe method was used to found the microbial taxa causing significant differences between the SHS and SUS (supplementary Fig. S4 and Fig. S5). As shown in Fig. S5, a total of 92 biomarkers were founded with an LDA threshold of 3.0. Most microbial clades were significantly enriched in SHS, while only 22 clades were enriched in SUS. Specifically, Actinobacteria (class), Chloroflexi (phylum), Deltaproteobacteria (class), Streptomycetaceae (family), Candidatus_Rokubacteria_noname (class),

Candidatus_Rokubacteria_noname (family), Candidatus_Rokubacteria (phylum) were enriched in SHS. Alphaproteobacteria (class), Rhizobiales (order), Bradyrhizobiaceae (family), Bradyrhizobium (genus), Rhodospirillales (order) were enriched in SUS.

\section{Variation on microbial metabolic pathways on the different slopes}

Based on the KEGG database, the functional contributions of the microbial community in the tiankeng soil samples were annotated. A total of 4786 KEGG orthologues (KO) were annotate and mainly belonging to metabolism, environmental information processing and genetic information processing (supplementary Fig. S6). Among the total of 42 functional pathways, the SHS had the higher genes number in 41 pathways (e.g., carbohydrate metabolism, amino acid metabolism, membrane transport and cellular community) (Fig. 4).

The LEfSe analysis was used to detected functional pathways with significant abundance differences between the shady slope and sunny slope. As shown in Fig. 5, the microbial community in shady slope was mainly involved in membrane transport, signal transduction, folding sorting and degradation, metabolism of cofactors and vitamins, metabolism of other amino acids, metabolism of terpenoids and polyketides, xenobiotics biodegradation and metabolism and endocrine system. However, the microbial community in sunny slope was mainly involved in signal transduction, cancers, xenobiotics biodegradation and metabolism, aging, biosynthesis of other secondary metabolites, energy metabolism, folding sorting and degradation, cell motility and translation.

Furthermore, microbial genes related to biomass conversion (CAZy genes) were annotated. CAZy (Carbohydrate-Active enzymes Database) is a professional database related to carbohydrate active enzymes, including related enzyme families that can catalyze carbohydrate degradation, modification and biosynthesis. CAZy contains six categories: Glycoside hydrolases (GHs), Glycosyltransferases (GTs), polysaccharide lyases (PLs), Carbohydrate esterases (CEs), Auxiliary activities (AAs) and CarbohydrateBinding Modules (CBMs). As shown in Fig. 6, the gene number of CAZy in SHS were higher than that in SUS. In addition, the significant differences on CAZy families were mainly belonging to GHs and GTs (Table S1).

\section{Relationships between different in microbial community composition and soil and plant variables}

The soil properties (SOM, TN, TP, TK, pH and SWC) and plant characteristics (Species richness, Cover and Shannon-Wiener index) were selected as environmental variables for microbial community (Fig. 7). RDA results showed that they could explain $46.6 \%$ of the microbial community composition variation. SOM, $\mathrm{pH}, \mathrm{SWC}$, species richness and coverage were the most key environmental variables influencing the 
composition of microbial community (explained for $74.9 \%, 62.15 \%, 68.4 \%, 59.2 \%$ and $83.2 \%$, respectively). Based on Spearman correlation coefficient, significant correlations were also found between soil or plant characteristics and microbial community (supplementary Fig. S7).

\section{Discussion}

\section{Effects of slope aspect on vegetation characteristics and soil physicochemical properties}

The inverted rock slope of the tiankeng serves as a bridge connecting the inside and the outside of the tiankeng, providing a breeding ground and seed propagation path for the plant community [20]. Studies have shown that slope aspect changes are an important cause of habitat heterogeneity. Accompanying differences in environmental factors such as light radiation, light duration, temperature, soil moisture and soil nutrients, which in turn affect the changes in the species composition and diversity of plant communities [21, 22]. Compared with the sunny slope, the shady slope has rich habitat resources and higher vegetation richness [23]. The deep sinking pond has a depth of $148.7 \mathrm{~m}$ and the west is a vertical cliff. The shaded slope is affected by the slope direction and the west vertical wall. The direct sunlight time is shorter than that of the sunny slope, and the amount of solar radiation is less than that of the sunny slope, which affects the vegetation distributed in the tiankeng. Our results founded that the dominant species on the shady slope were Myrsine africana Linn., Debregeasia orientalis C. J. Chen, Ternstroemia gymnanthera (Wight et Arn.) Beddome and the dominant species on the sunny slope were Quercus guyavifolia, Quercus variabilis BI. Every plant in the community does not exist in isolation, but is the result of interdependence and co-evolution with the species that make up the community in the habitat, and is affected by the habitat [24]. The vegetation species richness and coverage are significantly higher on the shady slope. Studies have shown that species diversity increases with soil moisture [25]. The soil moisture on the sunny slopes has a large amount of evaporation, and the soil layer is shallow and discontinuous due to rocky desertification, and the water is easy to lose, resulting in low soil moisture. In addition, SOM, TN and TK all show that the shade slope is higher than the sunny slope, which is consistent with Liu et al. studies [26]. In general, the shady slopes in the karst tiankeng have better vegetation coverage and soil nutrition.

\section{Effects of slope aspect on microbial community structure and function}

In the present study, the microbial community structure was differed between the sunny slope and shady slope. Microbial community diversity was significantly higher in shady slope, which may due to the shady slope have suitable habitat for microbial community [27]. Carletti et al. (2009) also found that soil microbial communities in sunny and shady slope were significantly different [28]. The PCoA analysis results also revealed a clear separation of microbial communities in different slope aspect (Fig. 2). The composition of the microbial community is similar on different slopes, but exhibits differences in microbial abundance. At the phylum level, Proteobacteria had the highest abundance in all soil samples, which were consistent with previous studies [4, 12]. In addition, Actinobacteria, Chloroflexi, Acidobacteria, Verrucomicrobia and Firmicutes were also abundant in all soil samples. Proteobacteria, Actinobacteria, 
Chloroflexi and Acidobacteria play a key role in organic matter transformation and nutrient cycle, which may suggested that microbes perform the strong metabolic capacity and nutrient degradation survive well in karst tiankeng [29]. At the genus level, Bradyrhizobium, Streptomyces, Acidobacteria_noname and Betaproteobacteria_noname. Bradyrhizobium have been regarded as dominant genera in soil [30]. The similar composition of the dominant genera indicates that tiankeng has a stable microbial community composition structure. However, the abundance of shared genera in different slope aspect is different, indicating that microorganisms with special functions can survive in different habitats in tiankeng. Therefore, different slope aspect of tiankeng has led to changes in the composition and structure of the microbial community. Furthermore, the most biomarkers of shady slope were belongs to Actinobacteria and Chloroflexi. However, the most biomarker of sunny slope was belongs to Proteobacteria. These results indicated that Actinobacteria, Chloroflexi and Proteobacteria were well adapted to the habitat in the karst tiankeng.

Based on metagenomic data, the function of microbiomes can be effectively analysed. In this study, the microbes were main involved in metabolic pathways. Carbohydrate metabolism, amino acid metabolism, energy metabolism, metabolism of cofactors and vitamins and nucleotide metabolism were enriched in microbiomes regardless of change in slope aspect. These pathways are essential for maintaining soil nutrient cycling and transformation [31]. The LDA results showed that the pathways biomarkers of shady slope were metabolism of other amino acids and xenobiotics biodegradation and metabolism. The pathways biomarkers of sunny slope were cell motility, translation and cell motility. It is worth noting that the microbial community on the sunny slopes were involved in human diseases. Zhou et al. (2019) research found that with the increase in the degradation of alpine grasslands, the number of most bacteria involved in human diseases is increasing [29]. Moreover, the abundance of CAZy genes was more abundant in shady slope. AA and GH are considered related to the decomposition of litter [32]. The higher abundance of $\mathrm{AA}$ and $\mathrm{GH}$ indicated that microorganisms from shady slope soil had stronger capability in litter decomposition. More abundant vegetation cover on shady slopes promotes nutrient cycling by producing more litter, which causes an increase in the abundance of CAZy genes. In general, the change in slope aspect affects the structure and function of the microbial community.

\section{Relationship among vegetation characteristics, soil properties and microbial community}

Microbial communities are sensitive indicators of vegetation and soil properties changes, and their interaction is considered to be the main driving factor of ecosystem functions [33]. Many studies have indicated that the difference in soil microbial community structure is mainly affected by the vegetation characteristics and soil properties $[19,34]$. The PCOA and AMOSIM analysis showed the microbial community of the shady and sunny slope were differed. The RDA and correlation results showed that the vegetation characteristics (species richness and coverage) and soil properties (SOM and $\mathrm{pH}$ ) were the main drivers of microbial community structure. The type of vegetation community determines the initial composition of the microbial community, and vegetation affects the structure of the microbial community by affecting the soil environment $[35,36]$. The soil SOM content in karst areas is severely affected by soil erosion and degradation [37]. The significant difference between the shady and sunny of 
SOM content may have affected the microbial communities. $\mathrm{pH}$ has been widely regarded as an important soil properties affecting microbial communities in karst areas $[4,38]$. Therefore, the difference in plant community composition and soil nutrients between shaded and sunny slopes is the main driving factor for the formation and evolution of microbial communities.

\section{Conclusions}

This study reveals the microbial community structure and functional characteristics of different slopes (shady and sunny slope) of karst tiankeng, which will help to deepen the understanding of the microbial diversity of karst tiankeng. The microbial communities Shannon-Wiener index was significantly higher in shady slope, and the microbial community structure differed between shay and sunny slope. The microbial communities at different slope aspect presented similar compositions but different abundances, and the dominant phyla were Proteobacteria, Actinobacteria, Chloroflexi and Acidobacteria. The main function pathways belongs to metabolism and environmental information processing. LEfSe results indicated several biomarker pathways in sunny slope involved in human disease. Moreover, the abundance of CAZy genes was higher in shady slope and had stronger ability in decomposing litter. The microbial community is mainly related to vegetation species richness, coverage, $\mathrm{SOM}$ and $\mathrm{pH}$.

\section{Methods}

\section{Study area}

The Zhanyi tiankeng group is located in Qujing County, Yunnan Province, China $\left(25^{\circ} 35^{\prime}-25^{\circ} 57^{\prime} \mathrm{N}\right.$, $\left.103^{\circ} 29^{\prime}-103^{\circ} 39^{\prime} \mathrm{E}\right)$. The Shenxiantang tiankeng is a representative degraded tiankeng in the Zhanyi tiankeng group (supplementary Fig. S8). The area belongs to the subtropical plateau monsoon climate. Average annual temperature is $13.8 \otimes 14{ }^{\circ} \mathrm{C}$, the annual rainfall is $1073.5 \otimes 1089.7 \mathrm{~mm}$, the annual total solar radiation energy is $123.8 \mathrm{kcal} \cdot \mathrm{cm}^{-2}$, and the average annual wind speed is $2.7 \mathrm{~m} \cdot \mathrm{s}^{-1}$. The rocks in the area are dominated by carbonatite and dolomite, and the soil in the horizontal zone of yunnan red soil. The characteristics of shenxiantang tiankeng have been reported in our previous research [20].

\section{Plant measurements and soil collection}

In July of 2019, five and four different slope sites with an area of $20 \times 20 \mathrm{~m}$ were selected in shady and sunny slope, respectively. In each site, three subplots were set along the diagonal, with an area of $5 \mathrm{~m} \times 5$ $\mathrm{m}$ were selected for the soil sampling. The plant coverage and dominant species were recorded. The plant community survey was only identified by observation and photographs, and comply with the Convention on the Trade in Endangered Species of Wild Fauna and Flora. The soil sample is collected from shenxiantang tiankeng and no need any permission. Five soil sampling were collected in each plot and then mixed to form a pooled soil sample. The fresh soil samples were stored in a plastic bag and transported to the laboratory. Parts of fresh soil sample were sieved $(<2 \mathrm{~mm})$ and air dried for 
characterizing the soil physical and chemical properties [39]. Parts of fresh soil sample were used for DNA extraction.

\section{DNA extraction and sequencing}

Microbial genomic DNA was extracted from $0.2 \mathrm{~g}$ fresh soil using the E.Z.N.A. ${ }^{\circledR}$ Soil DNA Kit (OMEGA, USA). The DNA quality and DNA concentration were assessed by agarose gel $(1 \%, w / v)$ electrophoresis and Qubit 2.0 fluorometer (Life Technologies). After genomic DNA quality inspection, the genomic DNA was cut into DNA fragments ( $\nabla 500 \mathrm{bp}$ ) using the Covaris S220 (Covaris Inc., Woburn, MA, USA). The library was constructed by using NEB Next ${ }^{\circledR}$ Ultra $^{\text {TM }}$ DNA Library Prep Kit ((Illumina, San Diego, CA, United States)) according to the manufacture's protocol. Paired-end sequencing was performed by PE150 (Illumina Inc., San Diego, CA, USA) at Sangon Biotech Co., Ltd (Shanghai, China).

\section{Processing of sequencing data}

Remove raw reads and get clean reads was performed by using Trimmomatic [40]. The stitching software IDBA_UD was used to assemble the clean reads and get contig [41]. Each contig of the open reading frames (ORFs) were predicted by using the Prodigal, and ORFs (length $\geq 100 \mathrm{bp}$ ) were chosen and translated them into protein sequences [42]. Clustering 95\% sequence identity of the gene sequences catalog and construct a nonredundant gene catalog were performed using CD-HIT (version 4.6) [43]. The Bowtie2 (version 2.1.0) and Samtools were used to get the abundance of gene in the sample [44]. DIAMOND (version 0.8.20) was used to compare assembled unigenes with $\mathrm{Nr}$ (NCBI non-redundant protein sequences) database for blastp homology to obtain functional annotation and homologous species information [45]. The KO numbers and pathways annotation information was obtained by compare protein sequence with KEGG database (Kyoto Encyclopedia of Genes and Genomes) using GhostKOALA (version 1.0) [46]. The carbohydrate enzymes active annotation by compare CAZy database (Carbohydrate-Active Enzymes) by using HMMER3 (version 3.1b1) [47].

\section{Data analysis}

All of the statistical analyses were via SPSS software (version 22.0). Based on a Bray-Curtis matrix Principal, the coordinates analysis (PCoA) was calculated in QIIME (version 1.9.0). The Linear discriminant analysis effect size (LEfSe) was used to discover the potential microbial taxa and functional biomarkers (http://huttenhower.sph.harvard.edu/galaxy/root?tool_id=PICRUSt_normalize). The multivariate redundancy analysis (RDA) was performed in Canoco (version 5.0). The analysis of similarities (ANOSIM) was finished in the $\mathrm{R}$ vegan package.

\section{Abbreviations}

Soil water content, SWC; Soil organic matter, SOM; Total nitrogen, TN; Total phosphorus, TP; Total potassium, TK. 


\section{Declarations}

\section{Ethics approval and consent to participate}

Not applicable

\section{Consent for publication}

Not applicable

\section{Availability of data and material}

The sequences were submitted to the SRA at NCBI under the accession number PRJNA749150.

\section{Competing interests}

The authors declare no conflict of interest

\section{Funding}

This work was supported by National Natural Science Foundation of China (No: 41871198).

\section{Authors' contributions}

C.J. and W.S. designed the study; C.J., S.F.Z. and J.F. performed the experiments, analyzed the data, and wrote the manuscript. All authors have read and approved the final manuscript.

\section{Acknowledgements}

Not applicable

\section{Author details}

${ }^{1}$ College of Urban and Environmental Sciences, Peking University, Beijing 100871, China; jcong@pku.edu.cn

${ }^{2}$ Chinese Research Academy of Environmental Sciences, Beijing 100020, China; zhu.sufeng@craes.org.cn

${ }^{3}$ College of Environment and Resources, Fuzhou University, Fuzhou 350116, China; n180627027@fzu.edu.cn

*Correspondence: shuiwei@fzu.edu.cn

\section{References}

1. Zhu X.W. China's karst tiankeng and its value for science and tourism. Sci. Technol Rev. 2001;10:60-63. 
2. Ozkan K, Gulsoy S, Mert A, Ozturk M, Muys B. Plant distribution-altitude and landform relationships in karstic sinkholes of Mediterranean region of Turkey. J Environ Biol. 2010;31(1-2):51-60.

3. Su Y, Tang Q, Mo F, Xue Y. Karst tiankengs as refugia for indigenous tree flora amidst a degraded landscape in southwestern China. Sci. Rep. 2017;7:4249.

4. Pu G, Lv Y, Dong L, Zhou L, Huang K, Zeng D, Mo L, Xu G. Profiling the Bacterial Diversity in a Typical Karst Tiankeng of China. Biomolecules 2019, 9(5):187.

5. Shui W, Chen Y, Wang Y, Su Za, Zhang S. Origination, study progress and prospect of karst tiankeng research in China. Acta Geographica Sinica. 2015;70(3):431-446.

6. Kovacic G, Ravbar N. Analysis of human induced changes in a karst landscape - the filling of dolines in the Kras plateau, Slovenia. Sci. Total Environ. 2013;447:143-151.

7. Liu C, Liu Y, Guo K, Zhao H, Qiao X, Wang S, Zhang L, Cai X. Mixing litter from deciduous and evergreen trees enhances decomposition in a subtropical karst forest in southwestern China. Soil Biol. Biochem. 2016;101:44-54.

8. Pu GZ, Wang KY, Mo L, Zeng DJ, Chen XX. Research progress on evolution and vegetation ecology of karst Tiankeng in China. Guihaia. 2021. DOI:10.11931/guihaia.gxzw202012032

9. Zhu XW, CW. Tiankengs in the karst of China. Cave Karst Sci. 2005;32(2):55-56.

10. Chen YP, Jiang C, Jian XM. Shui W, Hu Y, Ma T, Xiang ZY. Spatial distribution characteristics of grassland plant communities in a moderately degraded tiankeng in Zhanyi, Yunnan. Acta ecologica sinica. 2018;38(22):8008-8021.

11. Wei YL, Chen WH, Huang BJ. Geological relics formation mechanism and model of the Leye National Geopark, Guangxi. Acta Geogr Sin. 2010;65:580-594.

12. Jiang C, Feng J, Zhu SF, Shui W. Characteristics of the Soil Microbial Communities in Different Slope Positions along an Inverted Stone Slope in a Degraded Karst Tiankeng. Biology-Basel.2021;10.

13. Strickland MS, Lauber C, Fierer N, Bradford MA. Testing the functional significance of microbial community composition. Ecology. 2009;90(2):441-451.

14. Delgado-Baquerizo M, Oliverio AM, Brewer TE, Benavent-Gonzalez A, Eldridge DJ, Bardgett RD, Maestre FT, Singh BK, Fierer N. A global atlas of the dominant bacteria found in soil. Science. 2018;359(6373):320-+.

15. Bennie J, Huntley B, Wiltshire A, Hill MO, Baxter R: Slope, aspect and climate: Spatially explicit and implicit models of topographic microclimate in chalk grassland. Ecological Modelling. 2008; 216(1):4759. 
16. Sidari M, Ronzello G, Vecchio G, Muscolo A: Influence of slope aspects on soil chemical and biochemical properties in a Pinus laricio forest ecosystem of Aspromonte (Southern Italy). European Journal of Soil Biology. 2008; 44(4):364-372.

17. Huang YM, Liu D, An SS. Effects of slope aspect on soil nitrogen and microbial properties in the Chinese Loess region. Catena 2015;125:135-145.

18. Chu H, Xiang X, Yang J, Adams JM, Zhang K, Li Y, Shi Y. Effects of Slope Aspects on Soil Bacterial and Arbuscular Fungal Communities in a Boreal Forest in China. Pedosphere. 2016; 26(2):226-234.

19. Ai ZM, Zhang JY, Liu HF, Xue S, Liu GB: Influence of slope aspect on the microbial properties of rhizospheric and non-rhizospheric soils on the Loess Plateau, China. Solid Earth 2018; 9(5):1157-1168.

20. Feng J, Jiang C, Shui W, Zhu SF, Guo PP, Sun X, Zhang YY, Liu YM. Functional trait characteristics of Fagaceae plants in shady and sunny slopes in karst degraded tiankeng. Chinese Journal of Applied Ecology. 2021. DOI: 10.13287/j.1001-9332.202107.021

21. Chmura $D$. The slope aspect affects the heterogeneity and growth of ground flora vegetation in deciduous temperate forest. Polish Journal of Ecology. 2008; 56(3):463-470.

22. Stage AR, Salas C. Interactions of elevation, aspect, and slope in models of forest species composition and productivity. Forest Science. 2007; 53(4):486-492.

23. Small CJ, McCarthy BC. Spatial and temporal variability of herbaceous vegetation in an eastern deciduous forest. Plant Ecology. 2003; 164(1):37-48.

24. Parmesan C, Yohe G. A globally coherent fingerprint of climate change impacts across natural systems. Nature. 2003; 421(6918):37-42.

25. de Bello F, Leps J, Sebastia MT. Variations in species and functional plant diversity along climatic and grazing gradients. Ecography. 2006; 29(6):801-810.

26. Liu J, Qiu L, Wang X, Wei X, Gao H, Zhang Y, Cheng J. Effects of wildfire and topography on soil nutrients in a semiarid restored grassland. Plant and Soil. 2018; 428(1-2):123-136.

27. Liu Y, Zhang L, Lu J, Chen W, Wei G, Lin Y. Topography affects the soil conditions and bacterial communities along a restoration gradient on Loess-Plateau. Applied Soil Ecology. 2020;150.

28. Carletti P, Vendramin E, Pizzeghello D, Concheri G, Zanella A, Nardi S, Squartini A. Soil humic compounds and microbial communities in six spruce forests as function of parent material, slope aspect and stand age. Plant and Soil. 2009; 315(1-2):47-65

29. Zhou H, Zhang D, Jiang Z, Sun P, Xiao H, Wu Y, Chen J. Changes in the soil microbial communities of alpine steppe at Qinghai-Tibetan Plateau under different degradation levels. Science of the Total 
Environment. 2019; 651:2281-2291.

30. Shi P, Zhang Y, Hu Z, Ma K, Wang H, Chai T. The response of soil bacterial communities to mining subsidence in the west China aeolian sand area. Applied Soil Ecology. 2017;121:1-10.

31. Fuerch T, Preusse M, Tomasch J, Zech H, Wagner-Doebler I, Rabus R, Wittmann C. Metabolic fluxes in the central carbon metabolism of Dinoroseobacter shibae and Phaeobacter gallaeciensis, two members of the marine Roseobacter clade. Bmc Microbiolog. 2009; 9:209.

32. Cardenas E, Kranabetter JM, Hope G, Maas KR, Hallam S, Mohn WW. Forest harvesting reduces the soil metagenomic potential for biomass decomposition. Isme Journal. 2015; 9(11):2465-2476.

33. Fierer N, Jackson RB. The diversity and biogeography of soil bacterial communities. Proceedings of the National Academy of Sciences of the United States of America 2006, 103(3):626-631.

34. Bissett A, Richardson AE, Baker G, Wakelin S, Thrall PH. Life history determines biogeographical patterns of soil bacterial communities over multiple spatial scales. Molecular Ecology 2010; 19(19):43154327.

35. Wang G, Liu Y, Cui M, Zhou Z, Zhang Q, Li Y, Ha W, Pang D, Luo J, Zhou J. Effects of secondary succession on soil fungal and bacterial compositions and diversities in a karst area. Plant and Soil. 2021.

36. Liu M, Li X, Zhu R, Chen N, Ding L, Chen C. Vegetation richness, species identity and soil nutrients drive the shifts in soil bacterial communities during restoration process. Environmental Microbiology Reports. 2020; 13(4):411-424

37. Zhang L, Wang J-X, Xiao M-J, Liu B-Q. The Relation between Stability of Aggregates on Surface and SOM of Red Bare Soil in the Karst Area of East Yunnan, China. Advanced Materials Research. 2014; 10301032:920-925.

38. Santillan J, Lopez-Martinez R, Aguilar-Rangel EJ, Hernandez-Garcia K, Soledad Vasquez-Murrieta M, Cram S, Alcantara-Hernandez RJ. Microbial diversity and physicochemical characteristics of tropical karst soils in the northeastern Yucatan peninsula, Mexico. Applied Soil Ecology. 2021, 165. DOI:10.1016/j.apsoil.2021.103969.

39. Bao SD. Soil and Agricultural Chemistry Analysis. China Agriculture Press. 2000.

40. Bolger AM, Lohse M, Usadel B. Trimmomatic: a flexible trimmer for Illumina sequence data. Bioinformatics. 2014; 30(15):2114-2120.

41. Peng Y, Leung HCM, Yiu SM, Chin FYL. IDBA-UD: a de novo assembler for single-cell and metagenomic sequencing data with highly uneven depth. Bioinformatics. 2012; 28(11):1420-1428. 
42. Hyatt D, Gwo-Liang C, LoCascio PF, Land ML, Larimer FW, Hauser LJ. Prodigal. prokaryotic gene recognition and translation initiation site identification. BMC Bioinformatics 2010; 11(123-127):11.

43. Li W, Godzik A. Cd-hit: a fast program for clustering and comparing large sets of protein or nucleotide sequences. Bioinformatics 2006; 22(13):1658-1659.

44. Li H, Handsaker B, Wysoker A, Fennell T, Ruan J, Homer N, Marth G, Abecasis G, Durbin R, Genome Project Data P. The Sequence Alignment/Map format and SAMtools. Bioinformatics 2009; 25(16):20782079.

45. Buchfink B, Xie C, Huson DH. Fast and sensitive protein alignment using DIAMOND. Nature Methods 2015; 12(1):59-60.

46. Kanehisa M, Sato Y, Morishima K. BlastKOALA and GhostKOALA: KEGG Tools for Functional Characterization of Genome and Metagenome Sequences. Journal of Molecular Biology. 2016; 428(4):726-731.

47. Fontanez KM, Eppley JM, Samo TJ, Karl DM, DeLong EF. Microbial community structure and function on sinking particles in the North Pacific Subtropical Gyre. Frontiers in Microbiology. 2015; 6:469.

\section{Figures}




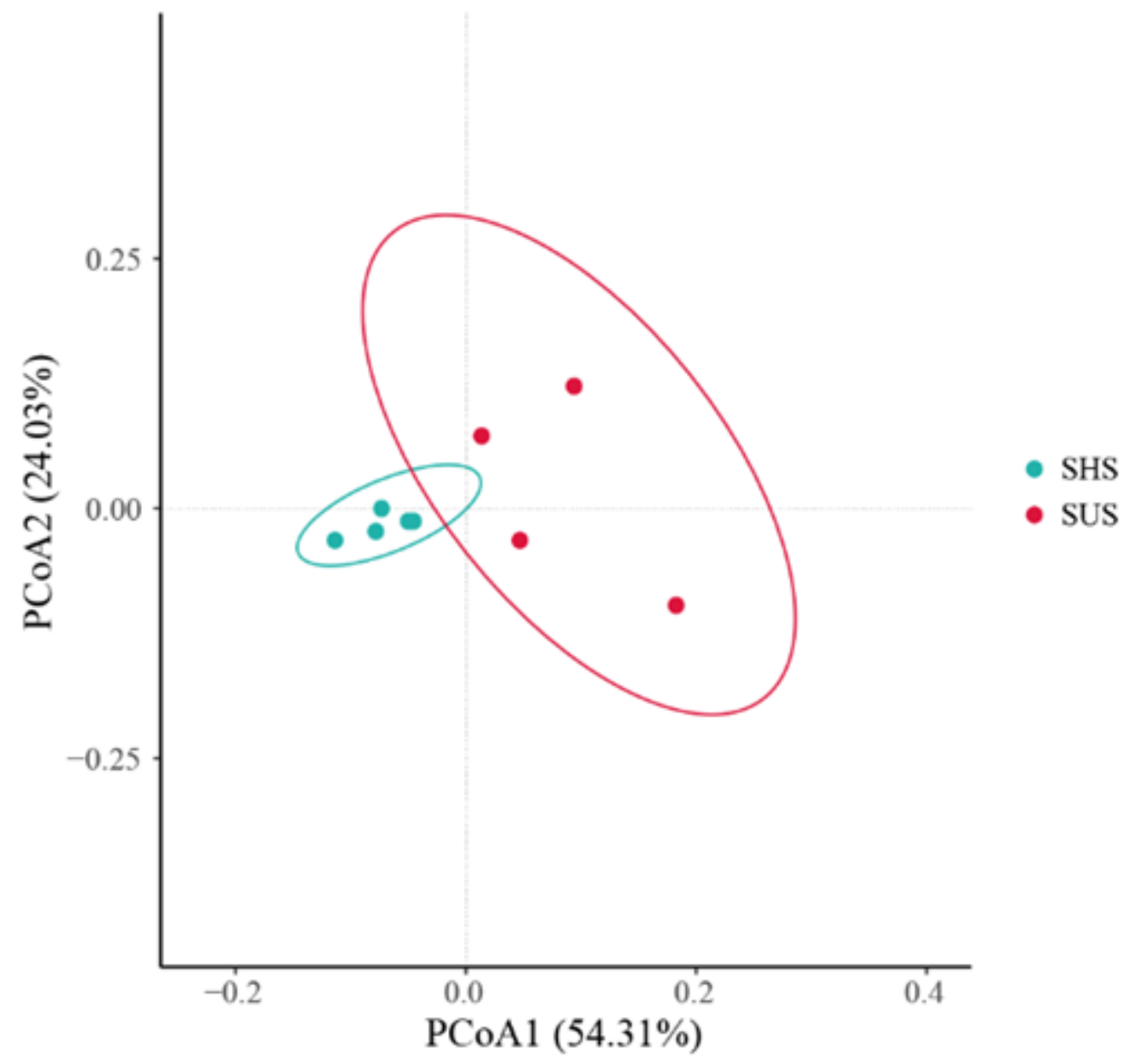

Figure 1

The principal coordinate analysis (PCOA) of microbial community on different slopes. 


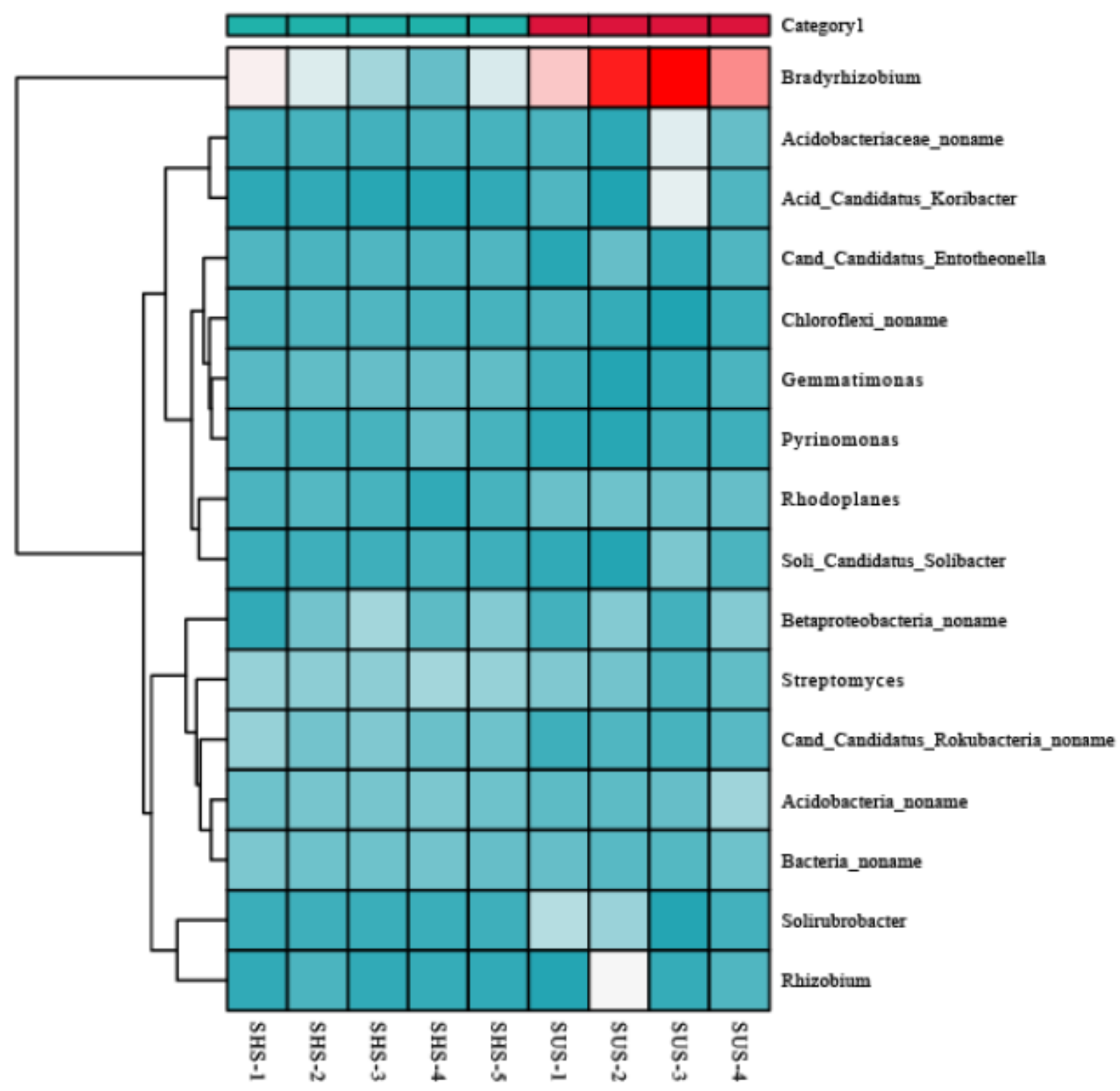

Figure 2

The microbial community composition on different slopes at the genus level. 


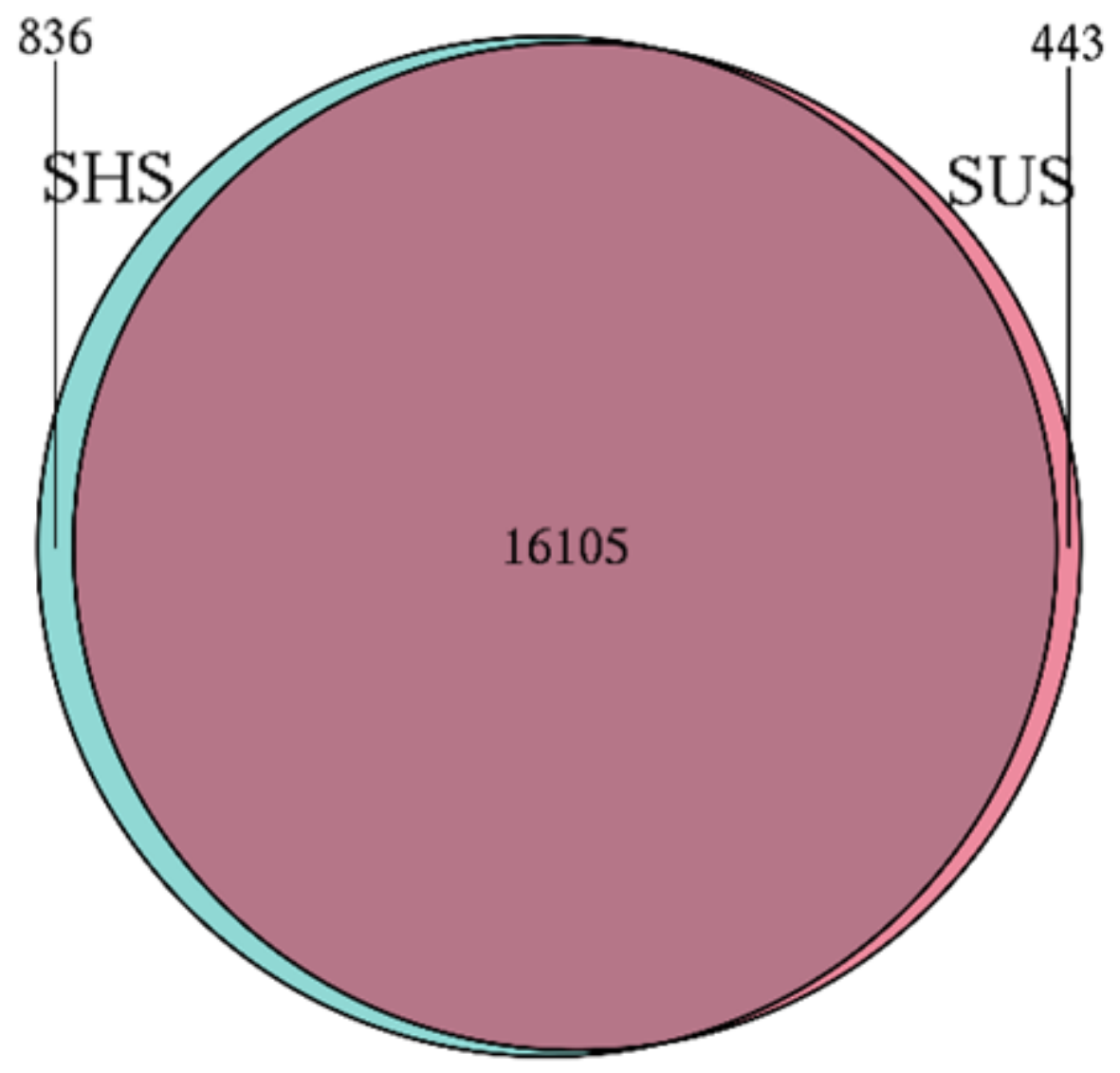

Figure 3

The similarity analysis of microbial community at the species level on different slopes. 


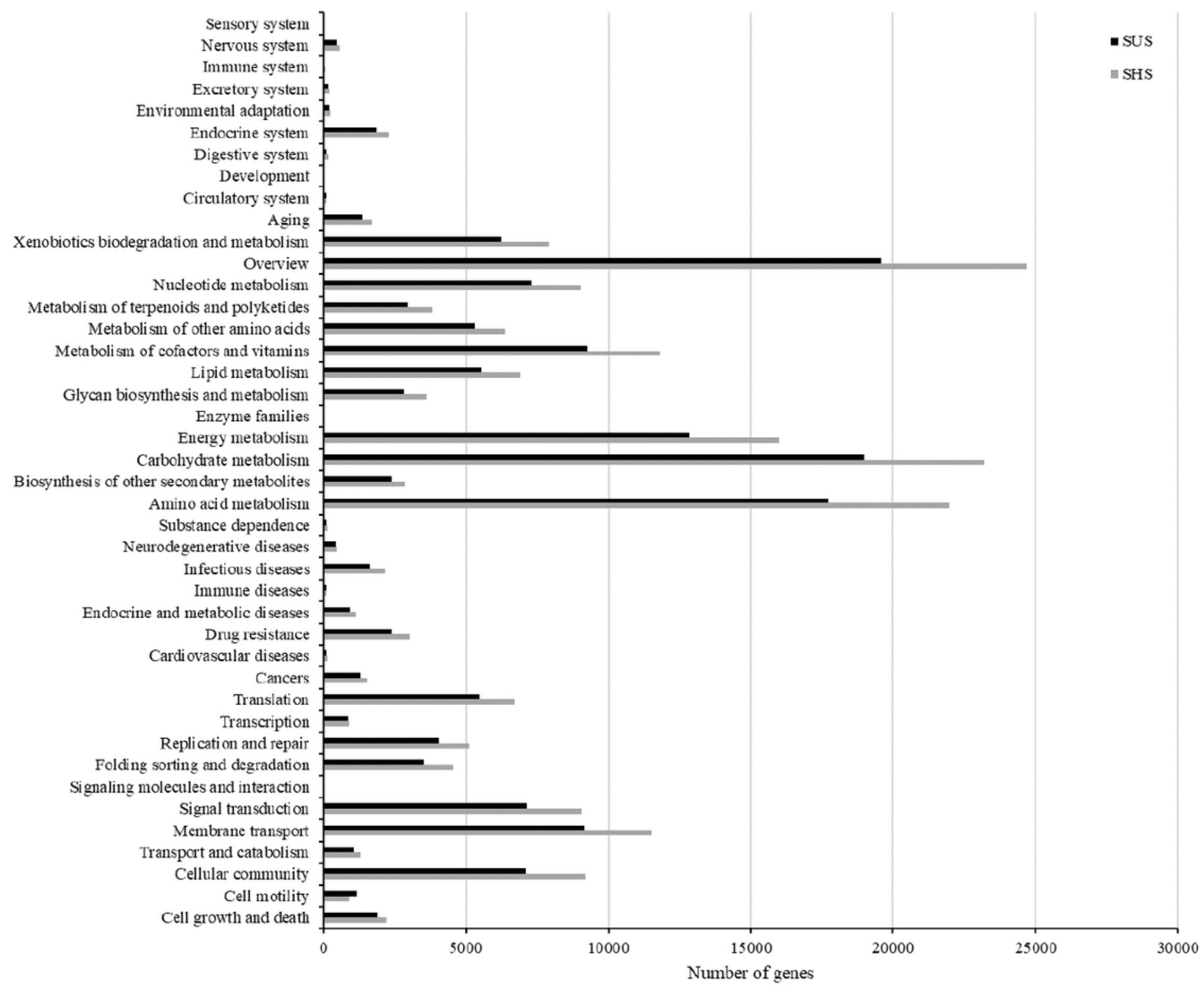

Figure 4

The number of genes associated with KEGG pathways on different slopes. 


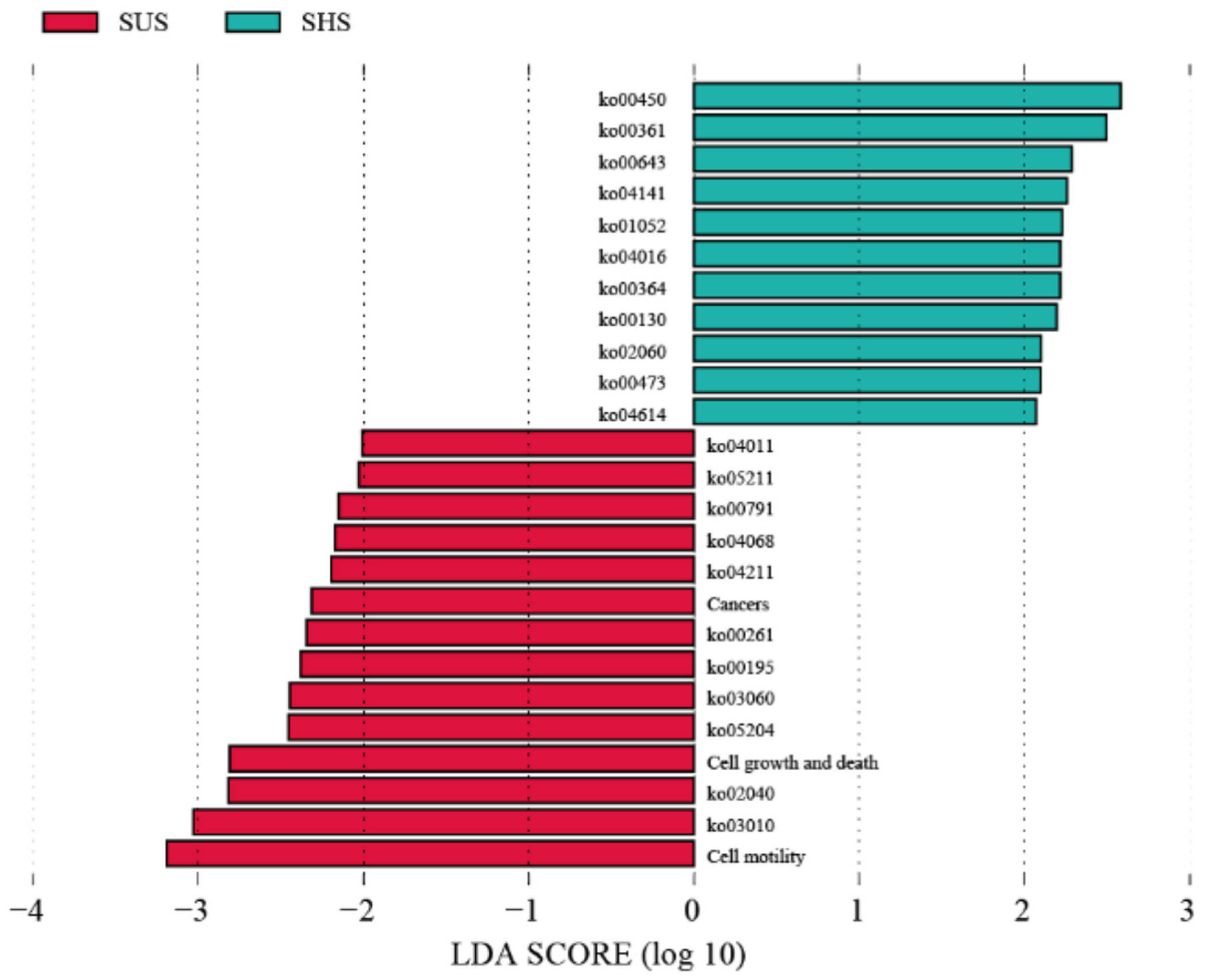

Figure 5

LEfSe analysis of functional categories (level 3) with significant differences on different slopes. 


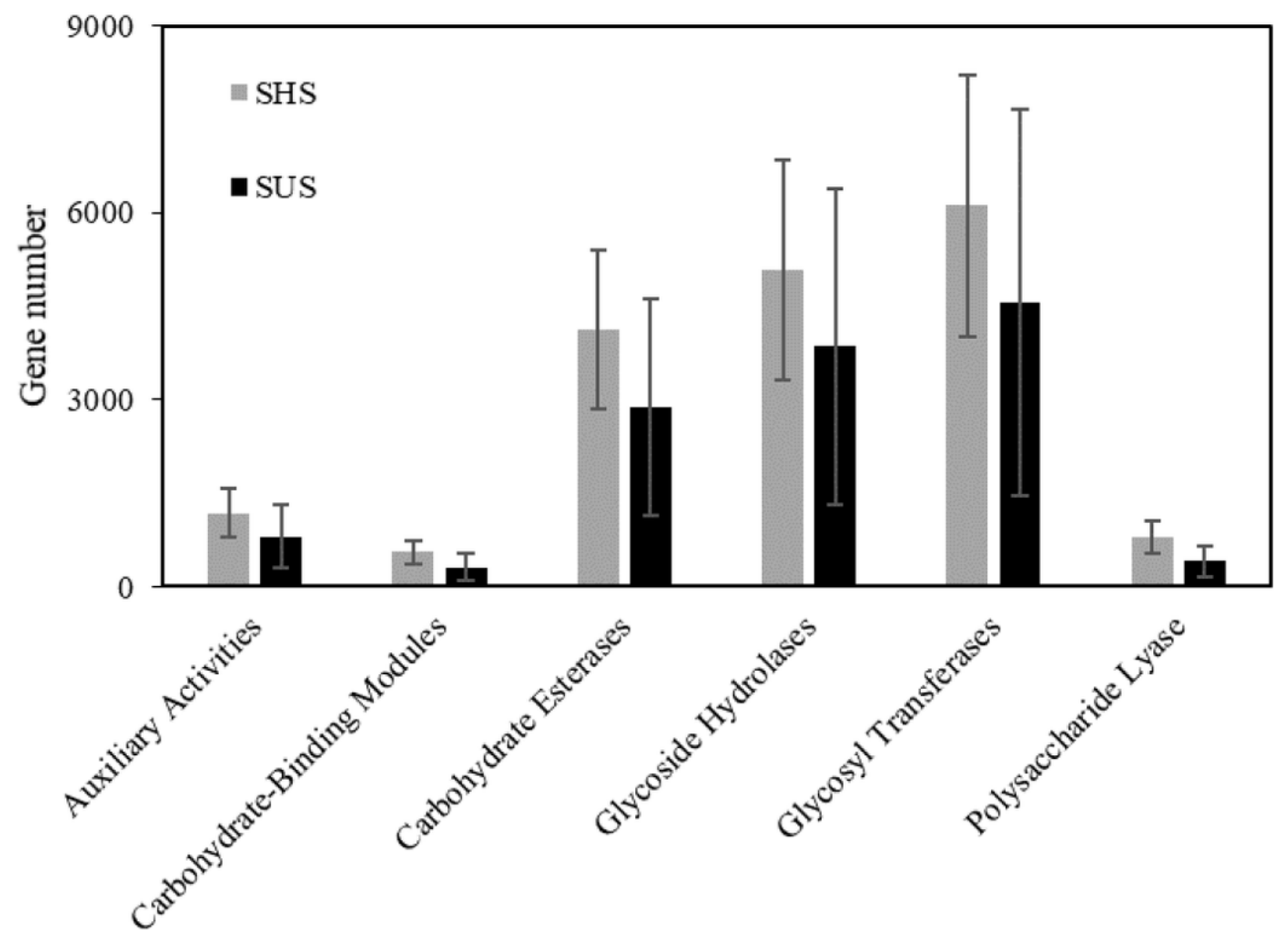

Figure 6

Variations of CAZy genes class number on different slopes. 


\section{Permutation test: $\mathrm{P}=0.007$}

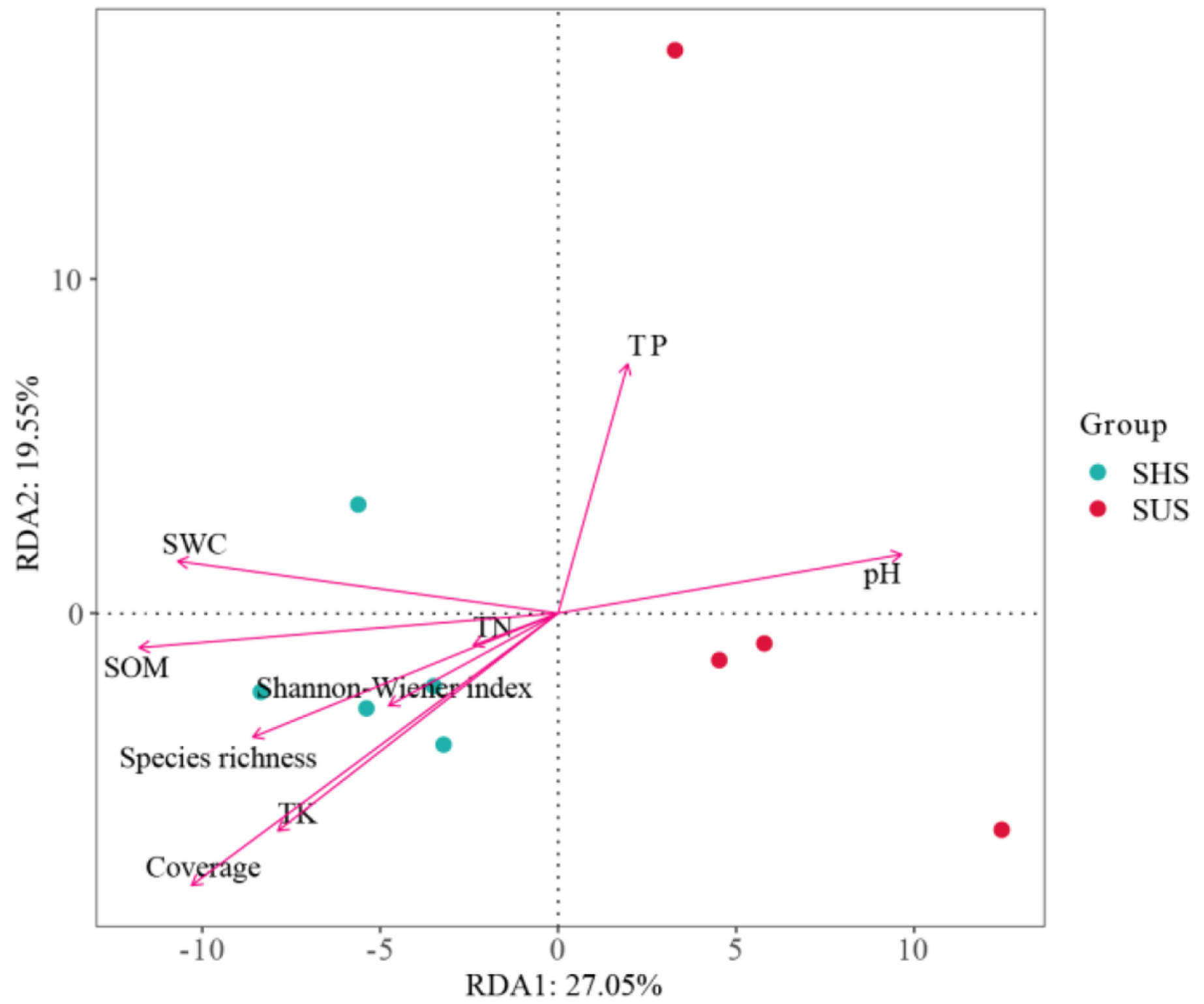

\section{Figure 7}

The redundancy analysis (RDA) of the soil characteristics or plant characteristics with microbial community on different slopes. Soil water content, SWC; Soil organic matter, SOM; Total nitrogen, TN; Total phosphorus, TP; Total potassium, TK.

\section{Supplementary Files}

This is a list of supplementary files associated with this preprint. Click to download.

- Supplementarymaterials.docx 